\title{
Body Mass Index and Mortality
}

\author{
Hye Jin Yoo* \\ Division of Endocrinology and Metabolism, Department of Internal Medicine, College of Medicine, Korea University, Seoul, Korea
}

\begin{abstract}
Although the prevalence of obesity, a well-known risk factor for various chronic diseases such as hypertension, type 2 diabetes and dyslipidemia, is rapidly increasing worldwide, the association of obesity with all-cause mortality remains controversial. Many previous epidemiologic studies have demonstrated a U-shaped relationship between obesity and mortality, suggesting that there is an obesity paradox. However, recent large-scale metaanalyses found contradictory results that both overweight and obese subjects exhibited a significant increase in all-cause mortality. This review summarizes the key epidemiologic studies on the association of obesity with mortality and thoroughly examines the causes of the obesity paradox and the precautions needed in the interpretation of this clinical evidence.
\end{abstract}

Key words: Obesity, Mortality, Body mass index, Waist circumference
Received February 16, 2017

Reviewed March 4, 2017

Accepted March 16, 2017

${ }^{*}$ Corresponding author

Hye Jin Yoo

http://orcid.org/0000-0003-0600-0266

Division of Endocrinology and Metabolism, Department of Internal Medicine, Korea University Guro Hospital, 148 Gurodong-ro, Guro-gu, Seoul 08308, Korea

Tel: +82-2-2626-3045

Fax: +82-2-2626-1096

E-mail: deisy21@naver.com

\section{INTRODUCTION}

The prevalence of obesity, defined as a body mass index (BMI) of 30 or greater, is rapidly increasing, up to $35.5 \%$ among adult men and $35.8 \%$ among adult women based on findings from the 20092010 National Health and Nutrition Examination Survey (NHANES). ${ }^{1}$ The Korean Society for the Study of Obesity noted that $32.8 \%$ of adult Koreans are obese: $36.1 \%$ of men and $29.7 \%$ of women. ${ }^{2}$ Obesity is defined as a BMI $\geq 25 \mathrm{~kg} / \mathrm{m}^{2}$ in Korea. Obesity, traditionally defined as a high BMI, exhibits an intimate association with incident chronic diseases, including hypertension, type 2 diabetes, cardiovascular diseases (CVD) and cancer. ${ }^{3}$ Obesity induces insulin resistance, proatherogenic states, unfavorable hemodynamic burden to the heart ${ }^{4}$, and promotes the growth of certain types of cancers such as breast and colorectal cancer. ${ }^{5}$ Although obesity is a well-known reversible risk factor for chronic diseases, there is still debate on the relationship between obesity and mortal- ity. Until now, many epidemiological studies have suggested that there is a U-shaped relationship between BMI and mortality. ${ }^{6-8} \mathrm{In}$ terestingly, the lowest hazard ratios (HR) for mortality have been observed in overweight or mildly obese individuals rather than in normal weight subjects. However, in 2016, large-scale meta-analyses reported results conflicting with these previous studies. Therefore, this review will briefly summarize the recent key meta-analyses on the relationship of elevated BMI with mortality and the potential causes of these contradictory results, focusing on the rationale for the obesity paradox.

\section{Recent key epidemiologic studies on the relationship} between elevated BMI and mortality

Association of BMI with mortality in the general population

(Table 1)

In 2016, various large-scale clinical studies reported on the relationship of BMI with mortality. One meta-analysis of 239 prospec- 
tive studies in four continents, including Asia, Australia and New Zealand, Europe, and North America, showed that all-cause mortality during a median follow-up of 13.7 years was minimal in individuals with a BMI of $20.0-25.0 \mathrm{~kg} / \mathrm{m}^{2}$ and increased significantly both above and just below this range. ${ }^{9}$ Importantly, to limit the effects of reverse causality, this meta-analysis excluded smokers, participants with chronic diseases at baseline and those dying within 5 years of recruitment. As a result, both being overweight and obesity were significantly associated with increased all-cause mortality, which contradicted previous results showing a protective effect of overweight and obesity on mortality and which indicated only severely obese people were at an increased risk of mortality. 8 Another recent meta-analysis of 230 cohort studies with 3.74 million deaths among 30.3 million participants also showed that the lowest mortality risk was detected at BMI $23-24 \mathrm{~kg} / \mathrm{m}^{2}$ in never smokers, $22-23 \mathrm{~kg} / \mathrm{m}^{2}$ in healthy never smokers and $20-22 \mathrm{~kg} / \mathrm{m}^{2}$ in never smokers with $\geq 20$ years of follow-up. ${ }^{10}$ In this study, the shape of the dose-response curve between BMI and mortality changed from a U-shape to a Jshape with increasing duration of follow-up, which is overall less influenced by the confounding factor of pre-diagnostic weight loss.

\section{Association of BMI with mortality in individuals with type 2 diabetes}

Compared to the general population, subjects with type 2 diabetes exhibit higher mortality, mainly caused by CVD. ${ }^{11}$ Although being overweight or obese is one of the modifiable risk factors for type 2 diabetes, the association between obesity and mortality in patients with type 2 diabetes remains controversial. A recent metaanalysis of 414,587 participants with type 2 diabetes showed that all-cause mortality was lowest in individuals with a BMI in the ranges of $31-35 \mathrm{~kg} / \mathrm{m}^{2}$ for men and $28-31 \mathrm{~kg} / \mathrm{m}^{2}$ for women ${ }^{12}$, while mortality was higher in normal weight subjects. Similarly, Wang et al. ${ }^{13}$ reported that the BMI value associated with the lowest mortality in individuals with type 2 diabetes was within the overweight range at $26.6 \mathrm{~kg} / \mathrm{m}^{2}$, even after adjusting for smoking, underlying diseases such as CVD, cancer, chronic bronchitis and renal disease, and excluding those who died during the first 3 years of follow-up. Thus, being overweight/obese conferred more protective effects against mortality than normal weight ${ }^{14}$ in individuals with type 2 diabetes compared to the general population. However, studies on the association of BMI with mortality in subjects with type 2 diabetes usually have short-term follow-up periods compared to studies of individuals without type 2 diabetes. Therefore, more large-scale studies with long-term follow-up are warranted to clarify the influence of obesity on mortality in diabetic patients.

\section{Association of BMI with mortality in Asians}

People in Asia have relatively higher visceral fat compared to members of other ethnic populations with the same BMI ${ }^{15}$ which contributes to the development of diabetes and CVD in individuals with relatively lower degrees of obesity. ${ }^{16}$ A World Health Organization (WHO) expert consultation proposed that Asians have an increased risk of type 2 diabetes and CVD at a lower BMI than the current WHO cut-off point for being overweight $\left(\geq 25 \mathrm{~kg} / \mathrm{m}^{2}\right) .{ }^{17}$ In 2000, the Asia-Pacific region redefined obesity as a BMI of $\geq 25$ $\mathrm{kg} / \mathrm{m}^{2}$ and overweight as $\geq 23 \mathrm{~kg} / \mathrm{m}^{2}$. However, the use of this cutoff was not directly supported by data on mortality. In a representative group of Chinese subjects, deaths from any cause were lowest among men with a BMI of 24.0 to 24.9 and women with a BMI of 25.0 to $24.9^{18,19}$ both of which are in the current overweight range in the Asia-Pacific guidelines. Yi et al. ${ }^{20}$ reported that the genderage specific optimal BMI value with minimal mortality was higher than the existing normal weight BMI range in Korean adults. Similarly, a 12-year prospective cohort study of $1,213,829$ Koreans showed that the risk of death from any cause was lowest among patients with a BMI of 23.0 to $24.9^{21}$, and recently updated data showed the lowest mortality in the $25-27.4 \mathrm{~kg} / \mathrm{m}^{2}$ BMI group (HR 0.88 ; 95\% CI, 0.80-0.97). ${ }^{22}$ Taken together, these findings suggest that the cutoff value of $<23 \mathrm{~kg} / \mathrm{m}^{2}$ for normal body weight in Asians might be too strict in terms of mortality.

\section{Causes of the obesity paradox}

The obesity paradox refers to the phenomenon that despite the harmful impact of obesity on risk factors associated with chronic diseases, overweight or obese individuals often exhibit a better prognosis than leaner patients. ${ }^{23}$ However, the obesity paradox may be due to both the inherent limitations in existing clinical studies, which falsely inflate the comparative survival advantage of patients with obesity, and the critical defects in using BMI to define obesity, which does not differentiate lean versus adipose tissue compart- 
Table 1. Large clinical studies about the relationship of BMI with mortality

\begin{tabular}{|c|c|c|c|c|c|c|}
\hline Author & Study type & Population & Study size & End point & $\begin{array}{l}\text { Follow-up } \\
\text { duration }\end{array}$ & Major findings \\
\hline Flegal et al. $(2013)^{8}$ & Meta-analysis & $\begin{array}{l}\text { General } \\
\text { population }\end{array}$ & $28,800,000$ & All-cause mortality & $1-42$ years & $\begin{array}{l}\text { OW }(25 \leq \mathrm{BMl}<30) \text { vs NW }(18.5 \leq \mathrm{BMl}<25) \text { subjects (HR 0.94; } 95 \% \mathrm{Cl} \text {, } \\
\text { 0.91-0.96) } \\
\text { OB (30 } \leq \mathrm{BMI}) \text { vs NW subjects (HR 1.18; } 95 \% \mathrm{Cl}, 1.12-1.25)\end{array}$ \\
\hline $\begin{array}{l}\text { The Global BMI } \\
\text { Mortality } \\
\text { Collaboration } \\
(2016)^{9}\end{array}$ & Meta-analysis & $\begin{array}{l}\text { General } \\
\text { population }\end{array}$ & $10,625,411$ & All-cause mortality & 13.7 years & 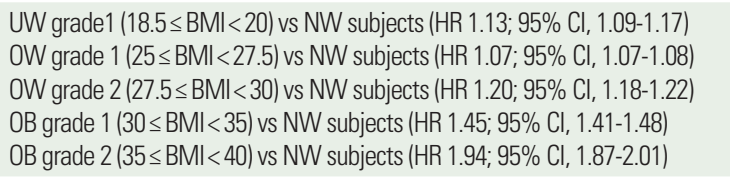 \\
\hline Aune et al. $(2016)^{10}$ & Meta-analysis & $\begin{array}{l}\text { General } \\
\text { population }\end{array}$ & $30,233,329$ & All-cause mortality & 13.8 years & $\begin{array}{l}\text { Never smoker: lowest mortality at BMI 23-24 } \\
\text { Healthy never smoker: lowest mortality at BMI 22-23 } \\
\text { Never smoker with } \geq 20 \text { years follow up: lowest mortality at BMI 20-22 }\end{array}$ \\
\hline Zaccardi et al. $(2017)^{12}$ & Meta-analysis & Type 2 Diabetes & 414,587 & All-cause mortality & $2.7-15.9$ years & Lowest mortality at BMI 31-35 (men) and 28-31 (women) \\
\hline Wang et al. $(2016)^{13}$ & Prospective & $\begin{array}{l}\text { Non-diabetes } \\
\text { Type } 2 \text { Diabetes }\end{array}$ & $\begin{array}{r}315,939 \\
25,458\end{array}$ & All-cause mortality & $2-12$ years & Lowest mortality at BMI 26.7 (non-diabetes) and 29.1 (type 2 diabetes) \\
\hline Gu et al. $(2006)^{18}$ & Prospective & Asians & 154,736 & $\begin{array}{l}\text { All-cause mortality } \\
\text { Cause specific } \\
\text { mortality }\end{array}$ & 8.3 years & $\begin{array}{l}\text { U-shaped association of BMl with all-cause mortality } \\
23 \leq \mathrm{BMl}<23.9 \text { (HR 1.09; 95\% Cl, 1.01-1.19), Reference BMl: 24.0-24.9 } \\
25 \leq \mathrm{BMl}<26.9 \text { (HR 1.00; } 95 \% \mathrm{Cl}, 0.92-1.08), 27.0 \leq \mathrm{BMI}<29.9 \text { (HR 1.15; 95\% } \\
\mathrm{Cl}, 1.06-1.24) \\
\text { Cause specific mortality (CVD, cancer and others): similar U-shaped pattern }\end{array}$ \\
\hline Yi et al. $(2015)^{20}$ & Prospective & Asians & $12,832,637$ & All-cause mortality & $9-12$ years & $\begin{array}{l}\text { Age specific optimal BMl: } 23.0-25.9 \text { at } 18-34 \text { years (men) } \\
24.0-27.9 \text { at } 45-54 \text { years } \\
25.0-28.9 \text { at } 65-74 \text { years } \\
15.5-24.9 \text { at } 18-34 \text { years (women) } \\
21.0-16.9 \text { at } 45-54 \text { years } \\
24.0-28.9 \text { at } 65-74 \text { years }\end{array}$ \\
\hline Jee et al. $(2006)^{21}$ & Prospective & Asians & $1,213,829$ & $\begin{array}{l}\text { All-cause mortality } \\
\text { Cause-specific } \\
\text { mortality }\end{array}$ & 12 years & $\begin{array}{l}\text { All-cause mortality: lowest at BMI 23.0-24.9 } \\
\text { Risk of death from respiratory causes: higher at a lower BMI } \\
\text { Risk of death from CVD and cancer: higher at a higher BMI }\end{array}$ \\
\hline Kim et al. $(2015)^{22}$ & Prospective & Asians & 153,484 & $\begin{array}{l}\text { All-cause mortality } \\
\text { CVD mortality } \\
\text { Cancer mortality }\end{array}$ & 7.91 years & $\begin{array}{l}\text { Lowest risk of all-cause mortality: BMI 24-26.4 (HR 0.86; 95\% Cl, 0.77-0.97, } \\
\text { reference BMl: 23-24.9) } \\
\text { Lowest riskof the elderly and those with chronic diseases: BMI 25-29.9 }\end{array}$ \\
\hline
\end{tabular}

OW, overweight; $\mathrm{BMI}$, body mass index; $\mathrm{NW}$, normal weight; $\mathrm{OB}$, obese; $\mathrm{HR}$, hazard ratio; $\mathrm{Cl}$, confidence interval; $\mathrm{CVD}$, cardiovascular diseases.

ments. Adipose tissue itself can shift its biological characteristics from an unhealthy phenotype towards a healthy phenotype, resulting in a true obesity paradox.

\section{Limitations of epidemiological studies on the obesity paradox}

Many methodological limitations of clinical studies such as selection, survival and treatment biases; a lack of controlling for confounding factors such as age, presence of chronic diseases, smoking and unmeasured factors; and inadequate follow-up length can lead to reverse causality and misconceptions about the nature of the obesity paradox.

\section{Aging and sarcopenic obesity}

Aging results in a progressive loss of muscle mass known as sarcopenia. ${ }^{24}$ Sarcopenic obesity is defined as the relative increase in fat mass and reduction in muscle mass, thereby leading to relative visceral fat accumulation at the same $\mathrm{BMI}^{25}$, and is a well-known risk factor for cardiovascular mortality. Because the elderly have a significant decrease in peripheral fat and a relative increase in abdominal fat, BMI adjusted for waist circumference (WC) probably reflects mostly lean mass and has been associated with favorable effects on mortality. ${ }^{26}$ In the elderly, BMI represents lean body mass better than body fat, which allows the protective effect of higher $\mathrm{BMI}$ on mortality to become more obvious. For example, Jee et al. ${ }^{21}$ showed that the highest relative risks associated with a high BMI were observed only in individuals less than 50 years old, whereas an increase in BMI more than $25.0 \mathrm{~kg} / \mathrm{m}^{2}$ was not associated with the risk of death among subjects who were 65 years older at baseline. Another meta-analysis observed a significant increase in optimal BMI according to age; optimal BMI was $23.0-25.9 \mathrm{~kg} / \mathrm{m}^{2}$ at $18-34$ years of age and $25.0-28.9 \mathrm{~kg} / \mathrm{m}^{2}$ at $65-74$ years of age in men and $15.5-24.9 \mathrm{~kg} / \mathrm{m}^{2}$ at $18-34$ years of age and $24.0-28.9 \mathrm{~kg} / \mathrm{m}^{2}$ at $65-74$ 
years of age in women ${ }^{20}$, emphasizing the necessity of age-specific guidelines for healthy body weight.

\section{Cardiorespiratory fitness}

Cardiorespiratory fitness $(\mathrm{CRF})$ is a well-known predictive factor for cardiovascular and all-cause mortality. ${ }^{27}$ A major study reported that for every increase in CRF by 1 metabolic equivalent (MET), the incidence of all-cause mortality was reduced by $13 \%$ and that of major cardiovascular events was reduced by $15 \%{ }^{28}$ Unfit individuals exhibit a higher risk of mortality about two times larger than that of fit normal-weight individuals irrespective of BMI, whereas fit overweight or obese individuals showed a similar risk of mortality compared to that of fit normal-weight individuals. ${ }^{29}$ Fitness includes critical contributions of muscle mass, and a high level of body fat indicates increased muscular mass. ${ }^{30}$ Therefore, a 'fit and fat' phenomenon might be a potential modifier in the association between $\mathrm{BMI}$ and mortality, which attenuates the increased mortality risk associated with higher BMI. ${ }^{31}$

\section{Underlying conditions including smoking history}

Underlying diseases result in loss of appetite and increased metabolic demands, causing unintentional weight loss. Because weight loss can precede the diagnosis of disease by many years, the association between low BMI and increased mortality might be caused by an undiagnosed illness. ${ }^{32}$ Smoking, which is also related with a lower weight, increases many specific causes of death. ${ }^{33}$ Therefore, limiting the analysis within healthy non-smokers usually attenuates the risk of death in underweight individuals and shows a tendency of higher risk of death with increasing BMI values. ${ }^{6}$ Stokes et al. ${ }^{34}$ demonstrated that overweight/obese never smokers exhibited a significantly higher mortality risk compared to individuals with a normal BMI (HR 1.51; 95\% CI, 1.07-2.15), whereas other studies showed that the U-shaped relationship of BMI with mortality did not change even after adjusting for these confounding factors.

\section{Follow-up duration}

A follow-up of less than 10 years is not sufficient time to develop obesity-related metabolic disturbances or to influence health. Obesity showed a definite close relationship with a higher risk of critical cardiovascular events with longer follow-up duration. ${ }^{35} \mathrm{~A}$ recent meta-analysis with a total of 299,059 participants reported that metabolically healthy overweight and obese individuals showed an increased risk of having CVD events, which appeared much stronger during a long-term follow-up period of more than 15 years, with pooled HRs of 1.47 (95\% CI, 1.37-1.58) in overweight and 2.00 (95\% CI, 1.79-2.24) in obese subjects. ${ }^{36}$ Therefore, to reduce the effect of reverse causation between BMI and mortality, many researchers performed subgroup analysis according to duration of follow-up and excluded the initial $2-5$ years of mortality data.

\section{Limitations of BMI as an obesity index}

A generalized obesity index such as BMI cannot fully reflect the risk of obesity-related metabolic complications. ${ }^{37}$ Abdominal obesity is more closely associated with the risk of several chronic diseases compared to generalized obesity, and large studies have suggested that the abdominal obesity indicators of WC or the waist-to-hip ratio (WHR) may be better predictors of the risk of disease than BMI. ${ }^{38}$ In a meta-analysis of six studies including 15,923 coronary heart disease subjects, central obesity based on tertiles of WHR or WC was associated with mortality (HR 1.70; 95\% CI, 1.58 to 1.83 ), whereas BMI was inversely associated with mortality (HR 0.64; 95\% CI, 0.59 to 0.69$).{ }^{39}$ Staiano et al. ${ }^{40}$ also reported that adults with a high WC had a higher mortality risk regardless of BMI obesity status when compared with low WC non-obese adults. Furthermore, the European Prospective Investigation into Cancer and Nutrition (EPIC) cohort study showed that the positive association between WC and mortality was stronger in individuals with a lower BMI. ${ }^{41}$ In that study, participants in the lowest third of BMI and the highest quintile of WC had the highest relative risk of death. Because of these types of findings, many researchers have asserted that WC should be considered in combination with BMI, even in subjects with normal and low BMIs, in order to accurately assess the risk of obesity related mortality. Therefore, the obesity paradox should not be confused with the BMI paradox, refuting the notion that obesity itself can be healthy in particular situations.

\section{Dynamic changes of adipocytes into healthy adipose tissue}

Recent evidence suggests that it is still true that certain obese individuals have a lower cardiometabolic risk. The phenotypes of adipose tissue can be diverse. Adipose tissues of increased infiltration 
with M1-polarized macrophages exhibit a pro-inflammatory and insulin resistant status ${ }^{42}$, whereas adipose tissues infiltrated with M2 macrophages show favorable adipokine expression and metabolic healthy profiles. ${ }^{43}$ Recently, the switch from white adipose tissue to brown or beige adipocytes has been found to provoke beneficial effects with regard to glucose tolerance and lipid homeostasis. ${ }^{44}$ In addition to such healthy changes in adipocytes, the location of fat accumulation can determine the overall effect of obesity on health risk. For example, the growth of subcutaneous adipose tissue deposition has advantageous effects on insulin resistance and fatty acid metabolism ${ }^{45}$, but epicardial adiposity detrimentally affects cardiovascular health. ${ }^{46}$ Therefore, better understanding of the biology, phenotype and function of adipose tissue will provide a pivotal key to clarifying the mechanism by which adipose tissue influences health and helps determine if the obesity paradox actually exists.

\section{CONCLUSION}

Obesity, defined as unhealthy adipose tissue accumulation, is a definite risk factor for chronic diseases. BMI may be an inaccurate index for assessing body fat distribution and discriminate between lean and fat mass. Current epidemiological studies have several inherent limitations in clarifying the relationship between obesity and mortality due to the use of BMI as an obesity index, various kinds of bias, lack of controlling for confounding factors, and insufficient follow-up duration. Furthermore, the impact of obesity on health can be very different according to age, gender, patient characteristics and the presence of comorbidities. Therefore, further research to develop a novel anthropometric index and determine its individualized cut-off points to estimate obesity risk should be completed, along with studies on the mechanism underlying adipocyte dysfunction and methods to preserve healthy fat.

\section{CONFLICTS OF INTEREST}

The author has no conflicts of interest.

\section{ACKNOWLEDGMENTS}

Dr. H. J. Yoo was supported by the Basic Science Research Pro- gram through the National Research Foundation of Korea (NRF), which is funded by the Ministry of Education, Science and Technology (2015R1A1A1A05001173).

\section{REFERENCES}

1. Flegal KM, Carroll MD, Kit BK, Ogden CL. Prevalence of obesity and trends in the distribution of body mass index among US adults, 1999-2010. JAMA 2012;307:491-7.

2. Kim MK, Lee WY, Kang JH, Kang JH, Kim BT, Kim SM, et al. 2014 clinical practice guidelines for overweight and obesity in Korea. Endocrinol Metab (Seoul) 2014;29:405-9.

3. Wilson PW, D’Agostino RB, Sullivan L, Parise H, Kannel WB. Overweight and obesity as determinants of cardiovascular risk: the Framingham experience. Arch Intern Med 2002;162: 1867-72.

4. Bastien M, Poirier P, Lemieux I, Després JP. Overview of epidemiology and contribution of obesity to cardiovascular disease. Prog Cardiovasc Dis 2014;56:369-81.

5. Kolb R, Sutterwala FS, Zhang W. Obesity and cancer: inflammation bridges the two. Curr Opin Pharmacol 2016;29:77-89.

6. Adams KF, Schatzkin A, Harris TB, Kipnis V, Mouw T, Ballard-Barbash R, et al. Overweight, obesity, and mortality in a large prospective cohort of persons 50 to 71 years old. N Engl J Med 2006;355:763-78.

7. Prospective Studies C, Whitlock G, Lewington S, Sherliker P, Clarke R, Emberson J, et al. Body-mass index and cause-specific mortality in 900000 adults: collaborative analyses of 57 prospective studies. Lancet 2009;373:1083-96.

8. Flegal KM, Kit BK, Orpana H, Graubard BI. Association of all-cause mortality with overweight and obesity using standard body mass index categories: a systematic review and metaanalysis. JAMA 2013;309:71-82.

9. Global BMIMC. Body-mass index and all-cause mortality: individual-participant-data meta-analysis of 239 prospective studies in four continents. Lancet 2016;388:776-86.

10. Aune D, Sen A, Prasad M, Norat T, Janszky I, Tonstad S, et al. BMI and all cause mortality: systematic review and non-linear dose-response meta-analysis of 230 cohort studies with 3.74 million deaths among 30.3 million participants. BMJ 2016; 
353:i2156.

11.Emerging Risk Factors C, Sarwar N, Gao P, Seshasai SR, Gobin R, Kaptoge S, et al. Diabetes mellitus, fasting blood glucose concentration, and risk of vascular disease: a collaborative meta-analysis of 102 prospective studies. Lancet 2010; 375:2215-22.

12.Zaccardi F, Dhalwani NN, Papamargaritis D, Webb DR, Murphy GJ, Davies MJ, et al. Nonlinear association of BMI with all-cause and cardiovascular mortality in type 2 diabetes mellitus: a systematic review and meta-analysis of 414,587 participants in prospective studies. Diabetologia 2017;60:240-8.

13. Wang Z, Dong B, Hu J, Adegbija O, Arnold LW. Exploring the non-linear association between BMI and mortality in adults with and without diabetes: the US National Health Interview Survey. Diabet Med 2016;33:1691-9.

14. Gruberg L, Weissman NJ, Waksman R, Fuchs S, Deible R, Pinnow EE, et al. The impact of obesity on the short-term and long-term outcomes after percutaneous coronary intervention: the obesity paradox? J Am Coll Cardiol 2002;39:578-84.

15. Park YW, Allison DB, Heymsfield SB, Gallagher D. Larger amounts of visceral adipose tissue in Asian Americans. Obes Res 2001;9:381-7.

16. Yoon KH, Lee JH, Kim JW, Cho JH, Choi YH, Ko SH, et al. Epidemic obesity and type 2 diabetes in Asia. Lancet 2006; 368:1681-8.

17. Consultation WHOE. Appropriate body-mass index for Asian populations and its implications for policy and intervention strategies. Lancet 2004;363:157-63.

18. Gu D, He J, Duan X, Reynolds K, Wu X, Chen J, et al. Body weight and mortality among men and women in China. JAMA 2006;295:776-83.

19. He J, Gu D, Wu X, Reynolds K, Duan X, Yao C, et al. Major causes of death among men and women in China. $\mathrm{N}$ Engl J Med 2005;353:1124-34.

20. Yi SW, Ohrr H, Shin SA, Yi JJ. Sex-age-specific association of body mass index with all-cause mortality among 12.8 million Korean adults: a prospective cohort study. Int J Epidemiol 2015;44:1696-705.

21.Jee SH, Sull JW, Park J, Lee SY, Ohrr H, Guallar E, et al. Bodymass index and mortality in Korean men and women. $\mathrm{N}$ Engl
J Med 2006;355:779-87.

22. Kim NH, Lee J, Kim TJ, Kim NH, Choi KM, Baik SH, et al. Body mass index and mortality in the general population and in subjects with chronic disease in Korea: a nationwide cohort study (2002-2010). PLoS One 2015;10:e0139924.

23. Lavie CJ, De Schutter A, Milani RV. Healthy obese versus unhealthy lean: the obesity paradox. Nat Rev Endocrinol 2015; 11:55-62.

24. Roubenoff R. Sarcopenic obesity: the confluence of two epidemics. Obes Res 2004;12:887-8.

25. Kohara K. Sarcopenic obesity in aging population: current status and future directions for research. Endocrine 2014;45:1525.

26. Villareal DT, Apovian CM, Kushner RF, Klein S. Obesity in older adults: technical review and position statement of the American Society for Nutrition and NAASO, The Obesity Society. Am J Clin Nutr 2005;82:923-34.

27. Yerrakalva D, Mullis R, Mant J. The associations of "fatness," "fitness," and physical activity with all-cause mortality in older adults: a systematic review. Obesity (Silver Spring) 2015;23: 1944-56.

28. Kodama S, Saito K, Tanaka S, Maki M, Yachi Y, Asumi M, et al. Cardiorespiratory fitness as a quantitative predictor of allcause mortality and cardiovascular events in healthy men and women: a meta-analysis. JAMA 2009;301:2024-35.

29. Barry VW, Baruth M, Beets MW, Durstine JL, Liu J, Blair SN. Fitness vs. fatness on all-cause mortality: a meta-analysis. Prog Cardiovasc Dis 2014;56:382-90.

30.Zavin A, Daniels K, Arena R, Allsup K, Lazzari A, Joseph J, et al. Adiposity facilitates increased strength capacity in heart failure patients with reduced ejection fraction. Int J Cardiol 2013; 167:2468-71.

31. McAuley PA, Beavers KM. Contribution of cardiorespiratory fitness to the obesity paradox. Prog Cardiovasc Dis 2014;56: 434-40.

32. Willett WC, Dietz WH, Colditz GA. Guidelines for healthy weight. N Engl J Med 1999;341:427-34.

33. Carter BD, Abnet CC, Feskanich D, Freedman ND, Hartge P, Lewis $\mathrm{CE}$, et al. Smoking and mortality--beyond established causes. N Engl J Med 2015;372:631-40. 
34. Stokes A, Preston SH. Smoking and reverse causation create an obesity paradox in cardiovascular disease. Obesity (Silver Spring) 2015;23:2485-90.

35. Kramer CK, Zinman B, Retnakaran R. Are metabolically healthy overweight and obesity benign conditions?: a systematic review and meta-analysis. Ann Intern Med 2013;159:75869.

36. Fan J, Song Y, Chen Y, Hui R, Zhang W. Combined effect of obesity and cardio-metabolic abnormality on the risk of cardiovascular disease: a meta-analysis of prospective cohort studies. Int J Cardiol 2013;168:4761-8.

37. Després JP. Body fat distribution and risk of cardiovascular disease: an update. Circulation 2012;126:1301-13.

38. Sahakyan KR, Somers VK, Rodriguez-Escudero JP, Hodge DO, Carter RE, Sochor O, et al. Normal-weight central obesity: implications for total and cardiovascular mortality. Ann Intern Med 2015;163:827-35.

39. Coutinho T, Goel K, Correa de Sa D, Kragelund C, Kanaya AM, Zeller M, et al. Central obesity and survival in subjects with coronary artery disease: a systematic review of the literature and collaborative analysis with individual subject data. J Am Coll Cardiol 2011;57:1877-86.

40. Staiano AE, Reeder BA, Elliott S, Joffres MR, Pahwa P, Kirkland $\mathrm{SA}$, et al. Body mass index versus waist circumference as predictors of mortality in Canadian adults. Int J Obes (Lond) 2012;36:1450-4.

41. Pischon T, Boeing H, Hoffmann K, Bergmann M, Schulze $\mathrm{MB}$, Overvad K, et al. General and abdominal adiposity and risk of death in Europe. N Engl J Med 2008;359:2105-20.

42. Fujisaka S, Usui I, Bukhari A, Ikutani M, Oya T, Kanatani Y, et al. Regulatory mechanisms for adipose tissue M1 and M2 macrophages in diet-induced obese mice. Diabetes 2009;58: 2574-82.

43. Lee MJ, Wu Y, Fried SK. Adipose tissue remodeling in pathophysiology of obesity. Curr Opin Clin Nutr Metab Care 2010; 13:371-6.

44. Stanford KI, Middelbeek RJ, Goodyear LJ. Exercise effects on white adipose tissue: beiging and metabolic adaptations. Diabetes $2015 ; 64: 2361-8$.

45. Hassinen M, Lakka TA, Komulainen P, Haapala I, Nissinen A, Rauramaa R. Association of waist and hip circumference with 12-year progression of carotid intima-media thickness in elderly women. Int J Obes (Lond) 2007;31:1406-11.

46. Mahabadi AA, Berg MH, Lehmann N, Kalsch H, Bauer M, Kara K, et al. Association of epicardial fat with cardiovascular risk factors and incident myocardial infarction in the general population: the Heinz Nixdorf Recall Study. J Am Coll Cardiol 2013;61:1388-95. 